\title{
Letter to Editor: A Concise Review of Intellectual Disability and Puberty Problems Based on the Laws of Different Countries
}

\author{
Shahrokh Mehrpisheh ${ }^{1}$ (D), Azadeh Memarian $^{2 *}$ iD, Kamran Aghakhani² $^{2}$ \\ 1. Department of Neonatology, Faculty of Medicine, Mazandaran University of Medical Sciences, Sari, Iran \\ 2. Department of Forensic \& Legal Medicine, Faculty of Medicine, Iran University of Medical Sciences, Tehran, Iran.
}

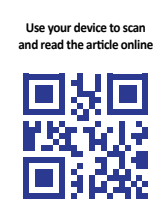

citation: Mehrpisheh Sh, Memarian A, Aghakhani K. A Concise Review of Intellectual Disability and Puberty Problems Based on the Laws of Different Countries. International Journal of Medical Toxicology and Forensic Medicine. 2020; 10(4):27266. https://doi.org/10.32598/ijmtfm.v10i4.27266

doi) $h$ htps://doi.org/10.32598/ijmtfm.v10i4.27266

\section{Dear Editor}

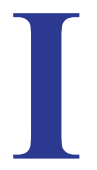

ntellectual Disability (ID) is characterized by limitations in intellectual functioning and behavioral adaptations. Patients with ID have a wide range of problems affecting the quality of life in these cases and their parents, as well.

The results of the current study showed that people with physical and learning disabilities should manage their sexuality and menstruation to improve their quality of life and reduce high-risk behaviors. Hormonal manipulation has been suggested as an effective approach for the management of many gynecological concerns in ID patients.

Multidisciplinary collaboration can effectively recognize the concerns of patients and their caretakers. In this regard, the legal and ethical aspects should be addressed to prevent the most vulnerable cases from sexual abuse in patients with ID. ID affects about $2 \%-3 \%$ of the general population [1].

The most important mental disorder in patients with ID during puberty is behavioral complaints [2]. It is es-sential to realize the function of patients with ID during puberty and maturity. Behavioral disorders generally exacerbate by about $3 \%$ to $4 \%$ during puberty [3].
People with ID experience poorer physical health and receive poorer quality health care than normal people due to several reasons, such as discrimination [4]

The most frequent menstruation problems and distressing symptoms in ID patients include impatience, hyper-activity, dysmenorrhea, menorrhagia, increased seizures, enhanced agitation, cyclical behavior disturbances, and self-mutilation $[5,6]$. Parents and caregivers concern about menstrual problems, hygiene, sexual abuse, pregnancy, and high-risk behaviors in ID patients [7-10].

In the Convention on the Rights of Persons with Disabilities, a basis was offered for protecting the rights of those people and some articles on involuntary sterilization were defined. Article 23 points to the right of persons with disabilities to have a family and maintain their fertility. Article 12 confirms their rights to enjoy legal capacity like other people. Another article mentions that informed consent is essential to provide health care for cases with disabilities [11].

In Islam, hysterectomy in women with ID is forbidden, unless there is a medical obligation because it may put them at risk. Parents are recommended to take care of their daughters giving them their rights and protecting them [12].

* Corresponding Author:

Azadeh Memarian, MD.

Address: Department of Forensic \& Legal Medicine, Faculty of Medicine, Iran University of Medical Sciences, Tehran, Iran.

Tel: +98 (21) 66551201

E-mail: memarian.a@iums.ac.ir 
Today, 15 states the United States still set the rules that do not protect the mentally retarded women from compulsory sterilization [13]. In the UK, the British Breeding Society and the National Association for the Care of Mental Retardation first tried to legislate the prevention of fertility in mentally retarded people, however, other committees did not support this proposal [14].

In Australia, the standard management for all ID women is to cause amenorrhea through some procedures and surgery and no cases were authorized by the court for sterilization. Accordingly, the United Nations Human Rights Council requested to prevent the sterilization in mentally retarded girls in Australia [15].

The results of the present study suggested that parents or caretakers should be informed about the puberty and menstruation process in adolescents with ID. However, the urgent need for asking advice from those who have experience about the puberty and menstrual period in ID patients to manage these cases has not been addressed in other studies. It can partly be due to the lack of skills and knowledge of healthcare providers to manage ID patients. In some countries, such as India, the social, cultural, and religious issues make parents asking for advice to manage their children with ID.

In conclusion, the results of the present study suggested that applying the suppressive methods is still used. Thus, sufficient knowledge makes parents and guardians less restrictive and aggressive. Further studies are required to provide better results and health care management for ID patients.

It is recommended to make a specific decision for cases with ID considering several characteristics, such as the severity of ID, learning ability, the personal condition, families' and caregivers' willingness, physical abilities, social and cultural levels of the family, ethics, gynecologists, psychiatrists, and legislators' viewpoints, and the religious beliefs in each country to deal with puberty problems in these patients.

\section{Ethical Considerations}

\section{Compliance with ethical guidelines}

All ethical principles were considered in this article.

\section{Funding}

This research did not receive any specific grant from funding agencies in the public, commercial, or not-for-profit sectors.

\section{Conflict of interest}

The authors declared no conflict of interest with respect to this manuscript.

\section{Acknowledgements}

The Authors would thanks Dr Azadeh Memarian for the guidence of this research.

\section{Reference}

[1] Hayes S, Shackell P, Mottram P, Lancaster R. The prevalence of intellectual disability in a major UK prison. British Journal of Learning Disabilities. 2007; 35(3):162-7. [DOI:10.1111/ j.1468-3156.2007.00461.x]

[2] Akrami L, Davudi M. Comparison of behavioral and sexual problems between intellectually disabled and normal adolescent boys during puberty in Yazd, Iran. Iranian Journal of Psychiatry and Behavioral Sciences. 2014; 8(2):68-74. https:/ / sites.kowsarpub.com/ijpbs/articles/3297.html

[3] Bradley EA, Summers JA, Wood HL, Bryson SE. Comparing rates of psychiatric and behavior disorders in adolescents and young adults with severe intellectual disability with and without autism. Journal of Autism and Developmental Disorders. 2004; 34(2):151-61. [DOI:10.1023/ B:JADD.0000022606.97580.19] [PMID]

[4] Hosking FJ, Carey IM, Shah SM, Harris T, DeWilde S, Beighton C, et al. Mortality among adults with intellectual disability in england: Comparisons with the general population. American Journal of Public Health. 2016; 106(8):1483-90. [DOI:10.2105/AJPH.2016.303240] [PMID] [PMCID]

[5] Schalock RL, Luckasson RA, Shogren KA, Borthwick-Duffy S, Bradley V, Buntinx WH, et al. The intellectual disability construct and its relation to human functioning. Intellectual and Developmental Disabilities. 2008; 46(4):311-8. [DOI:10.1352/1934-9556(2008)46[311:TIDCAI]2.0.CO;2] [PMID]

[6] Jeffery E, Kayani S, Garden A. Management of menstrual problems in adolescents with learning and physical disabilities. The Obstetrician \& Gynaecologist. 2013; 15(2):106-12. [DOI:10.1111/tog.12008]

[7] Burke LM, Kalpakjian CZ, Smith YR, Quint EH. Gynecologic issues of adolescents with Down syndrome, autism, and cerebral palsy. Journal of Pediatric and Adolescent Gynecology. 2010; 23(1):11-5. [DOI:10.1016/j.jpag.2009.04.005] [PMID] 
[8] Dizon CD, Allen LM, Ornstein MP. Menstrual and contraceptive issues among young women with developmental delay: A retrospective review of cases at the hospital for sick children, Toronto. Journal of Pediatric and Adolescent Gynecology. 2005; 18(3):157-62. [DOI:10.1016/j.jpag.2005.03.002] [PMID]

[9] van Schrojenstein Lantman-de HM, Walsh PN. Managing health problems in people with intellectual disabilities. The BMJ. 2008; 337:a2507. [DOI:10.1136/bmj.a2507] [PMID]

[10] ACOG Committee on Adolescent Health Care. ACOG Committee Opinion No. 349, November 2006: Menstruation in girls and adolescents: Using the menstrual cycle as a vital sign. Obstetrics and Gynecology. 2006; 108(5):1323-8. [DOI:10.1097/00006250-200611000-00059] [PMID]

[11] Stein S, Kohut T. Attitudes of parents related to the sexuality of adolescents with developmental disabilities compared to typically developing peers and siblings. Journal of Sexual Medicine. 2015; 12:283 https://www.researchgate. net/publication/288177154_ATTITUDES_OF_PARENTS_ RELATED_TO_THE_SEXUALITY_OF_ADOLESCENTS WITH_DEVELOPMENTAL_DISABILITIES_COMPARED_ TO_TYPICALLY_DEVELOPING_PEERS_AND_SIBLINGS

[12] Rana A. Hysterectomy of mentally disabled female: An ethical dilemma. Journal of Clinical Research \& Bioethics. 2020, 11:357. https://www.longdom.org/open-access/hysterectomy-of-mentally-disabled-female-an-ethical-dilemma. pdf

[13] McNeeley SG, Elkins TE. Gynecologic surgery and surgical morbidity in mentally handicapped women. Obstetrics and Gynecology. 1989; 74(2):155-8. [PMID]

[14] Jones K. Mental health and social policy, 1845-1959. London: Routledge \& Kegan Paul Ltd.; 1960. https://books. google.com/books/about/Mental_Health_and_Social_Policy_1845_195.html?id=hmjJZkSK4g8C

[15] Brady SM, Grover S. The sterilisation of girls and young women in Australia: 1997 report. Sydney: Australian Human Rights Commission. 1997. https://humanrights.gov.au/ our-work/disability-rights/projects/sterilisation-girls-andyoung-women-australia-1997-report\#full 
This Page Intentionally Left Blank 